\title{
Silent hypoxia: higher NO in red blood cells of COVID-19 patients
}

\author{
Esmaeil Mortaz ${ }^{1}$, Majid Malkmohammad ${ }^{2 *}$, Hamidreza Jamaati ${ }^{3}$, Parisa Adimi Naghan³, \\ Seyed MohamadReza Hashemian ${ }^{3}$, Payam Tabarsi ${ }^{1}$, Maohammad Varahram ${ }^{4}$, Hamidreza Zaheri ${ }^{3}$, \\ Efsun Gonca Uğur Chousein ${ }^{5}$, Gert Folkerts ${ }^{6}$ and lan M. Adcock,
}

\begin{abstract}
Background: Severe acute respiratory syndrome coronavirus 2 (SARS-CoV-2) that causes coronavirus disease 2019 (COVID-19) has spread to almost 100 countries, infected over $31 \mathrm{M}$ patients and resulted in $961 \mathrm{~K}$ deaths worldwide as of 21st September 2020. The major clinical feature of severe COVID-19 requiring ventilation is acute respiratory distress syndrome (ARDS) with multi-functional failure as a result of a cytokine storm with increased serum levels of cytokines. The pathogenesis of the respiratory failure in COVID-19 is yet unknown, but diffuse alveolar damage with interstitial thickening leading to compromised gas exchange is a plausible mechanism. Hypoxia is seen in the COVID-19 patients, however, patients present with a distinct phenotype. Intracellular levels of nitric oxide (NO) play an important role in the vasodilation of small vessels. To elucidate the intracellular levels of NO inside of RBCs in COVID-19 patients compared with that of healthy control subjects.
\end{abstract}

Methods: We recruited 14 COVID-19 infected cases who had pulmonary involvement of their disease, 4 nonCOVID-19 healthy controls (without pulmonary involvement and were not hypoxic) and 2 hypoxic non-COVID-19 patients subjects who presented at the Masih Daneshvari Hospital of Tehran, Iran between March-May 2020. Whole blood samples were harvested from patients and intracellular NO levels in $1 \times 10^{6}$ red blood cells (RBC) was measured by DAF staining using flow cytometry (FACS Calibour, BD, CA, USA).

Results: The Mean florescent of intensity for NO was significantly enhanced in COVID-19 patients compared with healthy control subjects $(P \leq 0.05)$. As a further control for whether hypoxia induced this higher intracellular NO, we evaluated the levels of NO inside RBC of hypoxic patients. No significant differences in NO levels were seen between the hypoxic and non-hypoxic control group.

Conclusions: This pilot study demonstrates increased levels of intracellular NO in RBCs from COVID-19 patients. Future multi-centre studies should examine whether this is seen in a larger number of COVID-19 patients and whether NO therapy may be of use in these severe COVID-19 patients.

Keywords: COVID-19, NO, Hypoxia

\footnotetext{
* Correspondence: mmalekmohammad@yahoo.com

${ }^{2}$ Tracheal Disease Research Center, National Research Institute of

Tuberculosisand Lung Diseases (NRITLD), Shahid Beheshti University of

Medical Science, Tehran, Iran

Full list of author information is available at the end of the article
}

C C The Author(s). 2020 Open Access This article is licensed under a Creative Commons Attribution 4.0 International License, which permits use, sharing, adaptation, distribution and reproduction in any medium or format, as long as you give appropriate credit to the original author(s) and the source, provide a link to the Creative Commons licence, and indicate if changes were made. The images or other third party material in this article are included in the article's Creative Commons licence, unless indicated otherwise in a credit line to the material. If material is not included in the article's Creative Commons licence and your intended use is not permitted by statutory regulation or exceeds the permitted use, you will need to obtain permission directly from the copyright holder. To view a copy of this licence, visit http://creativecommons.org/licenses/by/4.0/. The Creative Commons Public Domain Dedication waiver (http://creativecommons.org/publicdomain/zero/1.0/) applies to the data made available in this article, unless otherwise stated in a credit line to the data. 


\section{Background}

The coronavirus (severe acute respiratory syndrome coronavirus 2, SARS-CoV-2) that causes coronavirus disease 2019 (COVID-19) has spread to almost 100 countries, infected over 31 million patients and resulted in $961 \mathrm{~K}$ deaths worldwide as of 21st September 2020 [1]. The major clinical feature is acute respiratory distress syndrome (ARDS) with a key complication being heart and multi-functional failure. Normal blood oxygen saturation levels are at least $95 \%$ and this decreases in most lung diseases including pneumonia and is further decreased in the presence of stiff or oedematous lungs whilst increasing levels of carbon dioxide are usually seen in COVID-19 patients with pneumonia [2]. Thus, many COVID-19-infected patients with pulmonary involvement have hypoxia and dyspnea as important hallmarks of disease. Many COVID-19 patients are often alert and feeling relatively well and can easily talk despite the respiratory system being unable to sufficiently oxygenate blood a state known as 'happy' or silent hypoxia' [3].

Red blood cells (RBCs) are highly adapted cells for blood gas transport. At the high oxygen tensions (PO2) prevailing in the pulmonary system, the blood is normally completely saturated with oxygen and hemoglobin (Hb) will formed an $\mathrm{R}$ structure. When the blood enters the microcirculation, the $\mathrm{PO} 2$ is attenuated promoting oxygen dissociation from hemoglobin and a shift to the $\mathrm{T}$ form [4].

Clinical examination of severe cases of COVID-19 patients shows a decreased ratio of arterial oxygen partial pressure to fractional inspired oxygen $\left(\mathrm{PaO}_{2}: \mathrm{FiO}_{2}\right.$ ratio) with concomitant hypoxia and tachypnea in most cases [5]. Nitric oxide (NO) plays a key role in controlling the vascular system by regulating vascular tone and blood flow following activation of soluble guanylate cyclase (sGC) within the vascular smooth muscle. NO also controls mitochondrial oxygen consumption by inhibiting cytochrome $c$ oxidase [6]. RBCs have long been considered as powerful scavengers of endothelial cell-derived $\mathrm{NO}$, participating in systemic NO metabolism mainly by limiting NO bioavailability [7]. RBCs passing through the microcirculation sense tissue oxygen conditions via their degree of deoxygenation and couple this information to the release of vasodilatory compounds including ATP and NO to enhance blood flow to hypoxic tissues [8]. NO is a free radical and has a critical pathophysiological role in infectious diseases.

Intracellular NO within $\mathrm{RBCs}$ is derived from three sources: a) entry from the cell exterior by binding to the highly conserved $\beta$-globin chain cysteine 93 residue to form bioactive S-nitrosohemoglobin (SNO-Hb) [9], b) formation from nitrite entering $\mathrm{RBC}$ due to the reductive potential of deoxyhemoglobin [10] and c) intracellular production of $\mathrm{NO}$ by $\mathrm{RBC}$ derived from an active and functional eNOS-like enzyme (RBC NOS). RBC NOS is localized in the RBC membrane and cytoplasm and has similar properties to eNOS in terms of phosphorylation sites controlling enzymatic activity and its dependence on intracellular calcium and L-arginine concentrations for its activity [11].

Transfer of $\mathrm{NO}$ from $\mathrm{SNO}-\mathrm{Hb}$ to the membranebound anion exchanger (AE1) is required for transfer of $\mathrm{NO}$ out of the RBC and is dependent on both the SNO$\mathrm{Hb}$ state ( $\mathrm{T}$ or $\mathrm{R}$ ) and the $\mathrm{SNO}-\mathrm{Hb}$ concentration. Therefore, the ability of SNO-Hb to transfer NO to AE1 or other proteins such as glutathione are limiting factors in respiratory efficiency. The kinetics and allosteric regulation of $\mathrm{Hb}$ nitrosylation by oxygen and $\mathrm{pH}$ are consistent with the physiologic mechanisms that modulate tissue blood flow, namely acidosis and hypoxemia and tissue hypoxia leads to $\mathrm{NO}$ generation by the $\mathrm{RBC}$ via $\mathrm{SNO}-$ protein transfer of NO activity [12]. In addition, insults such as cellular stress activates RBC NOS, leading to NO release and vasodilation of vessel segments under hypoxic conditions. Together, this supports a prominent role of $\mathrm{RBC}$-derived $\mathrm{NO}$ in the regulation of local blood flow [13].

Therefore, the erythrocrine function of RBCs i.e. the release of bioactive molecules including NO, NO metabolites, and ATP are likely to be important in tissue protection and regulation of cardiovascular homeostasis by RBCs. Despite this clear role of NO in vasodilation, there is little evidence regarding the role of NO in COVID-19 particularly in silent hypoxic patients. To examine the hypothesis that NO is important in regulating vasodilation during hypoxia in these subjects we studied intracellular levels of NO in COVID-19 patients.

\section{Methods}

We examined 14 COVID-19 infected cases who had lung involvement of their disease, 4 non-COVID-19 healthy controls (without lung involvement and who were not hypoxic) and 2 hypoxic non-COVID-19 patients subjects who presented at the Masih Daneshvari Hospital of Tehran, Iran between March-May 2020. All COVID-19 infected cases were diagnosed based on the World Health Organization (WHO) interim guidance. Patients were confirmed positive for COVID-19 nucleic acid in the respiratory samples via real-time reverse-transcriptase polymerase-chain-reaction (RT-PCR) or serum specific antibodies and chest imaging including chest $\mathrm{X}$ ray and CT sacn. Demographic data of all participants is presented in Table 1. Red blood cells were isolated from $3 \mathrm{ml}$ whole blood cells with EDTA used as an anticoagulant. Whole blood was diluted 400-fold with FACS buffer (BSA and PBS) and then stained with the NO-specific probe, 4amino-5-methylamino-2', 7'-difluorofluorescein (DAF-FM DA) (BD Pharmingin, catalog 566,663, USA). Intracellular 
Table 1 Demographic information of all participants (COVID-19 and control groups)

\begin{tabular}{|c|c|c|c|c|c|c|c|c|c|c|}
\hline $\lg G$ & $\lg M$ & $\begin{array}{l}\text { RT-PCR } \\
\text { COVID-19 }\end{array}$ & Mortalility & Radialogy & Ventilation & PCO2 & $02 / \mathrm{S}$ & Sex & AGE & \\
\hline- & - & - & - & - & - & 41 & $92 / 97$ & $M$ & 39 & Control \\
\hline- & - & - & - & - & - & 40 & 98/97 & M & 65 & Control \\
\hline- & - & - & - & - & - & 40 & $97 / 98$ & $\mathrm{~F}$ & 44 & Control \\
\hline \multirow[t]{6}{*}{-} & - & - & - & - & - & 42 & $94 / 98$ & $\mathrm{~F}$ & 54 & Control \\
\hline & & + & + & ++ & MV & 56 & $69 / 86$ & $\mathrm{~F}$ & 80 & Patient 1 \\
\hline & & + & + & +++ & MV & 28 & $34 / 69$ & M & 77 & Patient 2 \\
\hline & & + & - & ++ & - & 47 & $61 / 87$ & M & 34 & Patient 3 \\
\hline & & + & + & ++ & MV & 44 & $26 / 51$ & $\mathrm{~F}$ & 62 & Patient 4 \\
\hline & & + & + & ++ & MV & 47 & $43 / 65$ & M & 72 & Patient 5 \\
\hline+ & + & - & + & ++ & - & 63 & $36 / 63$ & M & 69 & Patient 6 \\
\hline+ & + & - & + & ++ & MV & 47.5 & $47 / 82$ & M & 60 & Patient 7 \\
\hline+ & + & - & - & ++ & - & 55 & $48 / 80$ & M & 41 & Patient 8 \\
\hline+ & + & - & - & ++ & MV & 58.6 & $36 / 69$ & M & 66 & Patient 9 \\
\hline+ & + & - & - & ++ & - & 45 & 98/98 & M & 61 & Patient 10 \\
\hline+ & + & - & + & ++ & NIV & 41.4 & $81 / 82.5$ & $\mathrm{~F}$ & 74 & Patient 11 \\
\hline+ & + & - & - & ++ & - & 41 & $40.5 / 74.6$ & $\mathrm{~F}$ & 58 & Patient 12 \\
\hline+ & + & - & - & ++ & - & 44 & $84 / 97$ & $\mathrm{~F}$ & 81 & Patient 13 \\
\hline- & - & + & + & ++ & MV & 49 & $44 / 78$ & $\mathrm{~F}$ & 21 & Patient 14 \\
\hline
\end{tabular}

Abbreviation used: $M V$ Mechanical Ventilation, NIV Non-invasive Ventilation

In radiology: -, negative; +, Unilateral Ground glass opacity (GGO)/Consolidation, ++, Bilateral GGO/Consolidation; +++, ARDS

NO was detected by flow cytometry (FCM, BD FACS Calibour) using DAF-FM DA dye as a flurochrome. Following incubation of RBC cell suspensions for $30 \mathrm{~min}$ with the dye $(10 \mu \mathrm{M})$ a fluorescent signal was detected that corresponded to the level of intracellular NO.

\section{Results}

Chest X ray and CT imaging of the lungs shows significant changes in the lungs with bilateral alveolar diffusion confirming consolidation of the lungs in these patients (Fig. 1 a and b). In addition, patients with severe COVID-19 had higher serum lactate dehydrogenase (indicating tissue damage), C-reactive protein peaks (indicating inflammation) and lower counts of infectionfighting lymphocytes than those with milder disease. No significant differences were found in the levels of white blood cells, creatinine kinase (measuring muscle inflammation) or in lactic acid (measure of muscle oxygen levels) (Table 1). Having confirmed the clinical and radiographic features of COVID-19 in these subjects we then examined the levels of intracellular $\mathrm{NO}$ within their circulation RBCs.

Isolated RBC were stained with DAF and intracellular NO determined. COVID-19 patients had a rightward shift in the FACs plot reflecting higher intracellular levels of NO (Fig. 1c). The mean florescent intensity (MFI) was calculated for each subject and plotted as a histogram (Fig. 1d). This showed a significant increase in intracellular NO levels in RBCs from COVID-19 subjects $(P \leq 0.05)$.

To determine whether hypoxia itself may be responsible for the increased levels of intracellular $\mathrm{NO}$ in COVID-19 patient's RBC, we examined intracellular NO levels of RBC from hypoxic patients without COVID-19 (due to COPD and emphysema). As depicted Fig. 1e, no significant increase of intracellular NO was seen in hypoxic patients compared to non-hypoxic controls.

\section{Discussion}

We demonstrate increased levels of intracellular $\mathrm{NO}$ in RBC from COVID-19 subjects. This is not due to the presence of hypoxia per se but may afford protection against the hypoxia seen in COVID-19 patients. During health, constitutive NO production in RBCs is largely NOS-dependent, whereas in hypoxic conditions NO production may involve nitrite reduction by deoxyhemoglobin carbonic anydrase and/or eNOS itself [14].

RBC-derived NO causes the vasodilation of small vessels allowing oxygen to be readily released to tissues. In our study, intracellular RBC NO of COVID-19 patients is significantly higher than in healthy controls and this may enable the release of oxygen to tissues resulting in the clinical manifestation of silent hypoxia in these patients. Pronounced arterial hypoxemia without proportional 


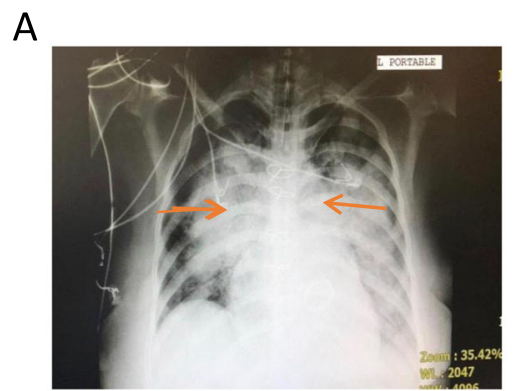

C

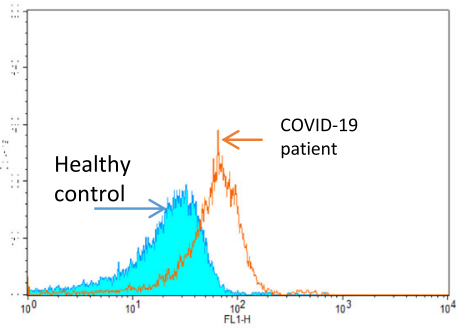

E

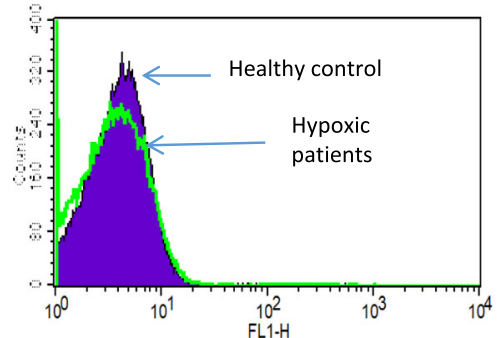

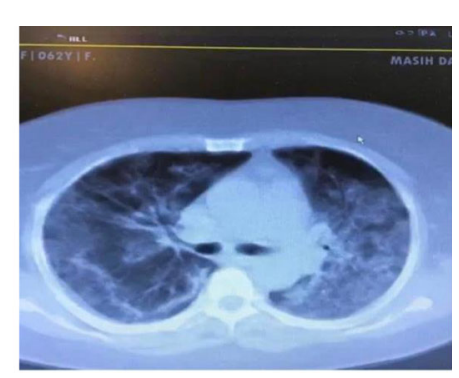

B

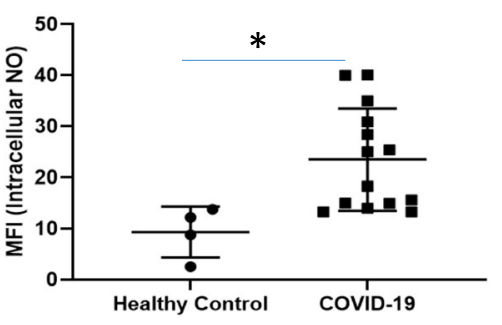

D

Fig. 1 a Representative chest X ray of a COVID-19 patient on mechanical ventilation showing bilateral consolidations (red arrows). b Spiral CT scan of a representative COVID-19 patient indicating multiple bilateral patchy ground glass infiltration. c Red blood cells were preincubated with $5 \mathrm{mM}$ of DAF for 20 min at $37^{\circ} \mathrm{C}$ in PBS containing 1\% BSA in the dark. Intracellular NO was determined by FACS analysis. A representative histograph from one out of 14 COVID-19 positive patients and 4 healthy controls is shown. $\mathbf{d}$ The mean fluorescent intensity (MFI) of all the subjects in each group is presented $\left({ }^{*} p<0.05\right.$ using Student's t-test). e Representative histogram of intracellular NO from RBCs of a single hypoxic non-COVID-19 patient

signs of respiratory distress is reported in COVID-19 patients [15-18]. For example, Tobin and colleagues recently reported three cases of silent hypoxemia with a $\mathrm{PaO} 2$ ranging between 36 and $45 \mathrm{mmHg}$ in the absence of increased alveolar ventilation [16].

However, the mechanism(s) underlying this silent hypoxia have not been explored despite the need to understand why some COVID-19 patients are able to continue with their normal daily activities despite often pronounced hypoxia [19].

Many theories have been proposed to account for this silent hypoxia. For example, silent hypoxia may be due to the differential effect of $\mathrm{O}_{2}$ and $\mathrm{CO}_{2}$ on gas exchange which may produce a relative preservation of the lungs' ability to excrete $\mathrm{CO}_{2}$ despite falling $\mathrm{O}_{2}$ levels. Since the body is better able to detect changes in $\mathrm{CO}_{2}$ than $\mathrm{O}_{2}$, the relatively normal $\mathrm{CO}_{2}$ levels may attenuate any drive to increase the patients breathing rate despite the presence of low oxygen levels and thereby prevent the sensation of shortness of breath.
The mechanism(s) underlying NO generation inside RBC is not well understood. However, acidosis, hypoxemia and tissue hypoxia lead to NO generation by RBC via SNO-protein transfer of NO activity [20, 21]. The efficiency of NO produced by RBC NOS to promote vasodilation is not well described however perfusion of blood vessel segments with pre-sheared RBC suspensions caused a significant dilation under hypoxic conditions, but not high oxygen, levels [22]. Vasodilation was abolished by pre-incubation of the RBC suspension with the NOS inhibitor L-NAME. These findings support the concept that RBC-derived NO has a functional role in the regulation of local blood flow [22]. Moreover, shear stress induces ATP release from hypoxic RBC as a consequence of their role as $\mathrm{O}_{2}$ sensors [21].

Since NO is a pulmonary vasodilator and also has antiviral activity against coronavirus strains it is likely that exogenous NO treatment may be effective in COVID-19 subjects. There is no evidence that direct oxygen therapy is beneficial in the management of breathlessness in 
severe COVID-19 patients but our data suggests that NO therapy may be beneficial in COVID-19 patients with hypoxia [23].

Autoimmune hemolytic anemia (AIHA) was recently described in COVID-19 patients [24, 25]. AIHA causes platelet cell death and RBCs can also modulate platelet activity directly through either chemical signalling or direct RBC-platelet interactions. In this way RBCs promote platelet aggregation and degranulation by releasing ATP and ADP under low $\mathrm{pO}_{2}$, low $\mathrm{pH}$ and in response to mechanical deformation $[26,27]$. In addition, the release of extracellular hemoglobin can also cause platelet activation by lowering NO bioavailability [28]. Thus, our current finding and evidence for hemolysis in patients may account for the microvascular coagulation seen in COVID-19 patients. We were unable to explore the mechanism(s) causing the accumulation of intracellular $\mathrm{NO}$ in RBC of COVID-19 patients in this study but this will be the focus of future research.

In summary, COVID-19 patients show higher levels of NO inside RBC compared to non-COVID-19 hypoxemic patients. Whether higher levels of intracellular NO inside RBC of COVID-19 infected patients drive the unexpected silent hypoxia phenotype needs to be examined in future clinical studies using $\mathrm{NO}$ donors in hypoxemic COVID-19 patients.

\section{Conclusions}

This pilot study shows that elevated levels of intracellular NO may mask the effects of hypoxia in COVID-19 patients that presents as a silent hypoxic state. Further studies are required to confirm this but the data suggests that trials of NO therapy or NO donors may be useful in treating severe COVID-19 patients with hypoxia.

\section{Abbreviations}

ARDS: Acute Respiratory Distress Syndrome (ARDS); COVID-19: coronavirus disease 2019 (COVID-19; FACS: Fluorescence-activated cell sorting; MFI: Mean florescent of intensity; NO: Nitric oxide; RBC: Red blood cells

\section{Acknowledgements}

We acknowledge all study participants who are alive and remember those patients who died of COVID-19.

\section{Authors' contributions}

EM performed the experiments and initial data analysis. MM, HRJ, PANN, SMRH, PT, MV and HZ provided the patients and samples. EGC, GF and IMA critically reviewed and revised the manuscript. All authors reviewed the final version and approved submission.

\section{Funding}

This study was supported by the authors own funds.

\section{Availability of data and materials}

The data will be available upon written request.

\section{Ethics approval and consent to participate}

The study was approved by Ethical committee of Masih Daneshvari Hospital IR (SBMU.NRITLD.REC.1399.123) and written consent was obtained from the study participants or their next of kin.
Consent for publication

All participants has consent for publication form.

\section{Competing interests}

The authors have no conflicts of interest to declare.

\section{Author details}

${ }^{1}$ Clinical Tuberculosis and Epidemiology Research Center, National Research Institute of Tuberculosis and Lung Diseases (NRITLD), Shahid Beheshti University of Medical Sciences, Tehran, Iran. ${ }^{2}$ Tracheal Disease Research Center, National Research Institute of Tuberculosisand Lung Diseases (NRIT LD), Shahid Beheshti University of Medical Science, Tehran, Iran. ${ }^{3}$ Chronic Respiratory Diseases Research Center, National Research Institute ofTuberculosis and Lung Diseases (NRITLD), Shahid Beheshti University of Medical Sciences, Tehran, Iran. ${ }^{4}$ Mycobacteriology Research Center, National Research Institute of Tuberculosis and Lung Diseases (NRITLD), Masih Daneshvari Hospital, Shahid Beheshti University of Medical Sciences, Tehran, Iran. ${ }^{5}$ University of Health Sciences Turkey, Yedikule Chest Diseases and Thoracic Surgery, Education and research Hospital, Department of pulmonology, Istanbul, Turkey. ${ }^{6}$ Division of Pharmacology, Utrecht Institute for Pharmaceutical Sciences, Faculty of Science, Utrecht University, Utrecht, Netherlands. ${ }^{7}$ Cell and Molecular Biology Group, Airways Disease Section, Faculty of Medicine, National Heart and Lung Institute, Imperial College London, London, UK. ${ }^{8}$ Priority Research Centre for Asthma and Respiratory Disease, Hunter Medical Research Institute, University of Newcastle, Newcastle, NSW, Australia.

Received: 3 July 2020 Accepted: 9 October 2020

Published online: 16 October 2020

\section{References}

1. Nile SH, Nile A, Qiu J, Li L, Jia X, Kai G. COVID-19: Pathogenesis, cytokine storm and therapeutic potential of interferons. Cytokine Growth Factor Rev. 2020:53:66-70.

2. Pedersen SF, Ho Y-C. SARS-CoV-2: a storm is raging. J Clin Invest. 2020; 130(5):2202-5. https://doi.org/10.1172/JC1137647.

3. Yuki K, Fujiogi M, Koutsogiannaki S. COVID-19 pathophysiology: A review. Clin Immunol. 2020;215:108427. https://doi.org/10.1016/j.clim.2020.108427.

4. Soy M, Keser G, Atagündüz P, Tabak F, IşıkAtagündüz SK. Cytokine storm in COVID-19: pathogenesis and overviewof anti-inflammatory agents used in treatment. Clin Rheumatol. 2020;39:2085-94.

5. Wang D, Hu B, Hu C, Zhu F, Liu X. Clinical characteristics of 138 hospitalized patients with 2019 novel coronavirus-infected pneumonia in Wuhan, China. JAMA. 2020;7(323):1061-9.

6. Chen G, Wu D, Guo W, Cao Y, Huang D, Wang H, et al. Clinical and immunological features of severe and moderate coronavirus disease 2019. J Clin Invest. 2020:130(5:2620-9. https://doi.org/10.1172/JCl137244.

7. Cameron MJ, Bermejo-Martin JF, Danesh A, Muller MP, Kelvin DJ. Human immunopathogenesis of severe acute respiratory syndrome (SARS). Virus Res. 2008;133:13-9.

8. Magro G. SARS-CoV-2 and COVID-19: is interleukin-6 (IL-6) the 'culprit lesion' of ARDS onset? What is there besides Tocilizumab? SGP130Fc. Cytokine X. 2020;2(2):100029. https://doi.org/10.1016/j.cytox.2020.100029.

9. Han H, Ma Q, Li C, Liu R, Zhao L, Wang W, Zhang P, Liu X, Gao G, Liu F, Jiang Y, Cheng X, Zhu C, Xia Y. Profiling serum cytokines in COVID-19 patients reveals IL- 6 and IL-10 are disease severity predictors. Emerg Microbes Infect. 2020;9(1):1123-30. https://doi.org/10.1080/22221751.2020. 1770129.

10. Zhang Y, Wang X, Li X, Xi D, Mao R, Wu X, Cheng S, Sun X, Yi C, Ling Z, Ma L, Ning Q, Fang Y, Sun B, Wu D. Potential contribution of increased soluble IL-2R to lymphopenia in COVID-19 patients. Cell Mol Immunol. 2020;17(8): 878-80. https://doi.org/10.1038/s41423-020-0484-x.

11. Grivennikov SI, Tumanov AV, Liepinsh DJ, et al. Distinct and nonredundant in vivo functions of TNF produced by T cells and macrophages/neutrophils: protective and deleterious effects. Immunity. 2005;22:93-104.

12. Tay MZ, Poh CM, Rénia L, Paul A, MacAry, Lisa F, Ng P. The trinity of COVID19: immunity, inflammation and intervention, vol. 20; 2020. p. 363-74.

13. Horiuchi T, Mitoma H, Harashima S-i, Tsukamoto H, Shimoda T. Transmembrane TNF-a: Structure, function and interaction with anti-TNF agents. Rheumatology (Oxford, England). 2010;49:1215-28. 
14. Ware CF, Crowe PD, Vanarsdale TL, Andrews JL, Grayson MH, Jerzy R, et al. Tumor necrosis factor (TNF) receptor expression in T lymphocytes. Differential regulation of the type I TNF receptor during activation of resting and effector T cells. J Immunol. 1991;147:4229-38.

15. Tobin MJ, Laghi F, Jubran A. Why COVID-19 silent hypoxemia is baffling top physicians. Am J Respir Crit Care Med. 2020; Available from: http://www. ncbi.nlm.nih.gov/pubmed/32539537.6; [cited 2020 Jun 23].

16. Couzin-Frankel J. The mystery of the pandemic's'happy hypoxia'. Science. 2020;368(6490):455-6. https://doi.org/10.1126/science.368.6490.455.

17. Wilkerson RG, Adler JD, Shah NG, Brown R. Silent hypoxia: a harbinger of clinical deterioration in patients with COVID-19. Am J Emerg Med. 2020; W. B. Saunders; Available from:https://pubmed.ncbi.nlm.nih.gov/32471783/.8;

18. Allali G, Marti C, Grosgurin O, Morélot-Panzini C, Similowski T. Adler D.Dyspnea: the vanished warning symptom of COVID-19 pneumonia. J MedVirol. 2020; jmv.26172 Wiley; [cited $2020 \mathrm{Jul}$ 4]. Available from:https://onlinelibrary.wiley. com/doi/abs/10.1002/jmv.26172).

19. Doctor A, Platt R, Sheram ML, Eischeid A, McMahon T, Maxey T, et al. Hemoglobin conformation couples erythrocyte S-nitrosothiol content to $\mathrm{O}_{2}$ gradients. Proc Natl Acad Sci U S A. 2005;102:5709-14.

20. Singel DJ, Stamler JS. Chemical physiology of blood flow regulation by red blood cells: the role of nitric oxide and S-nitrosohemoglobin. Annu Rev Physiol. 2005;67:99-145.

21. Ulker P, Gunduz F, Meiselman HJ, Baskurt OK. Nitric oxide generated by red blood cells following exposure to shear stress dilates isolated small mesenteric arteries under hypoxic conditions. Clin Hemorheol Microcirc. 2013:54:357-69.

22. Ellsworth ML, Ellis CG, Goldman D, Stephenson AH, Dietrich HH, Sprague RS Erythrocytes: oxygen sensors and modulators of vascular tone. Physiology (Bethesda). 2009;24:107-16.

23. Pimentel-Muinos FX, Seed B. Regulated commitment of TNF receptor signaling: a molecular switch for death or activation. Immunity. 1999;11: 783-93.

24. Lazarian G, Quinquenel A, Bellal M, et al. Autoimmune hemolytic anemia associated with Covid-19 infection. Br J Haematol. 2020. https://doi.org/10. 1111/bjh.16794 [published online ahead of print, 2020 may 6.

25. Lopez C, Kim J, Pandey A, Huang T, DeLoughery TG. Simultaneous onset of COVID-19 and autoimmune hemolytic anemia. Br J Haematol. 2020. https:// doi.org/10.1111/bjh. 16786 .

26. Reimers RC, Sutera SP, Joist JH. Potentiation by red blood cells of shearinduced platelet aggregation: relative importance of chemical and physical mechanisms. Blood. 1984;64:1200-6.

27. Sprague RS, Ellsworth ML, Stephenson AH, et al. ATP: the red blood cell link to NO and local control of the pulmonary circulation. Am J Phys. 1996;271: H2717-22.

28. Helms CC, Marvel M, Zhao W, et al. Mechanisms of hemolysis-associated platelet activation. J Thromb Haemost. 2013;11:2148-54.

\section{Publisher's Note}

Springer Nature remains neutral with regard to jurisdictional claims in published maps and institutional affiliations.

Ready to submit your research? Choose BMC and benefit from:

- fast, convenient online submission

- thorough peer review by experienced researchers in your field

- rapid publication on acceptance

- support for research data, including large and complex data types

- gold Open Access which fosters wider collaboration and increased citations

- maximum visibility for your research: over $100 \mathrm{M}$ website views per year

At BMC, research is always in progress.

Learn more biomedcentral.com/submissions 